Frayssc B, Deguine O (eds): Cochlear Implants: New Perspectives. Adv Otorhinolaryngol. Basel, Karger, 1993, vol 48, pp 44-48

\section{Steady State Evoked Potentials: A New Tool for the Accurate Assessment of Hearing in Cochlear Implant Candidates}

G. Rance ${ }^{\text {a }}$, F.W. Rickards ${ }^{\mathrm{b}}$, L.T. Cohen ${ }^{\mathrm{a}}$, M.J. Burton a G.M. Clark ${ }^{a}$ Department of Otolaryngology, and ${ }^{b}$ Deafness Studies Unit, Institute of Education, University of Melbourne, Parkville, Australia

Precise determination of residual hearing in prospective cochlear implant candidates is essential. As the minimum age of implantation for young children has reduced, the use of objective measures of hearing has become more important. At the University of Melbourne Cochlear Implant Clinic, steady state evoked potential (SSEP) assessments are routinely carried out on all candidates under the age of 5 years using a microcomputer and custom-designed hardware in the manner described by Cohen et al. [1].

Steady state evoked potentials are scalp potentials elicited in response to sinusoidally amplitude and/or frequency modulated tones. The resulting potential is periodic, and is phase locked to the modulation envelope of the stimulus.

Good estimations of behavioural thresholds have been reported across a range of carrier frequencies $(250-4,000 \mathrm{~Hz})$, in both normal and hearingimpaired awake adults using SSEP testing techniques at repetition rates of $40 \mathrm{~Hz}[2,3]$. In addition to these findings, Cohen et al. [1] demonstrated that the response can be elicited by stimuli at low sound pressure levels in sleeping adults if modulation rates above $70 \mathrm{~Hz}$ are used. We have also successfully employed these high modulation frequencies to test sleeping neonates, obtaining results consistent with those seen in awake and sleeping adults, and suggesting that this technique is suitable for use as a measure of hearing acuity in sleeping children [4]. Furthermore, Rickards et al. [5] showed good agreement between SSEP thresholds and tone pip elicited
$A B R$ thresholds to stimuli at 500 and $4,000 \mathrm{~Hz}$, in a group of 20 neonates.

This paper presents the preliminary findings for a study examining the elationship between the SSEP thresholds observed in a group of young cocher implant candidates, with thresholds obtained behaviourally. Data from a similar study involving hearing-impaired adults is also included.

Methods

Subjects in this study were 25 severely/profoundly hearing impaired children (12 ind 13 (emate). The median age of this group was 28 months with a range of $10-58$ months at the time of the SSEP craluation. In addition, the results of 35 adults (23 malc

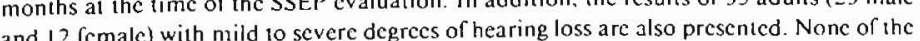
and in the case of the adults. retrocochlear subjects showed, ysfunction.

Subjects' hearing sensitivity was assessed behaviourally using a standard clinical procedure, with pure or warble tones and a clinical audiometer. Results werc obtained in the free field or under headphones as diclated by the age of the child.

At the line of the SSEP data collecion, the adults were in natural slecp. and the

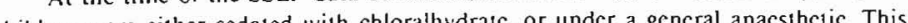
assessment was typically carried out on the occasion of the child's $C T$ scans.

Stimulus generation, recording procedures and waveform analysis were the same as described previously by Cohen $\mathrm{ct}$ al. [1]. The presenec or absence of a response was determined automatically using a detcction criterion which looked for non-random phase bchaviour in regular samples of the scalp potentials. The stimuli, presented via mu-metal sereened TDH- 39 headphones, were purc tones amplitude and frequency modulated at a rate of $90 \mathrm{~Hz}$. Carrier frequencics from $250 \mathrm{~Hz} 104.000 \mathrm{~Hz}$ werc tesicd (typically in octave increments). The maximum sound levels of the slimuli were 104 dBHL for the 250-Hz carrier, and $120 \mathrm{dBHL}$ for the 500-, 1,000-, 2,000- and 4,000-Hz carricr frequen-

\section{Results}

Figure 1 shows the plot of SSEP thresholds ( $Y$ ) versus clinical behavoural thresholds $(\mathrm{X})$ obtained for all of the subjects using a 1-kHz stimulus together with the appropriate linear regression line. The slope of less than unity and positive intercept reflects the better threshold accuracy seen in ears with a greater degree of hearing loss. Regression lines drawn for other carrier frequencies followed a similar pattern.

A comparison of actual and predicted SSEP thresholds was carricd out for each of the carrier frequencies. In 395 of the 412 comparisons ( $96 \%$ ), 


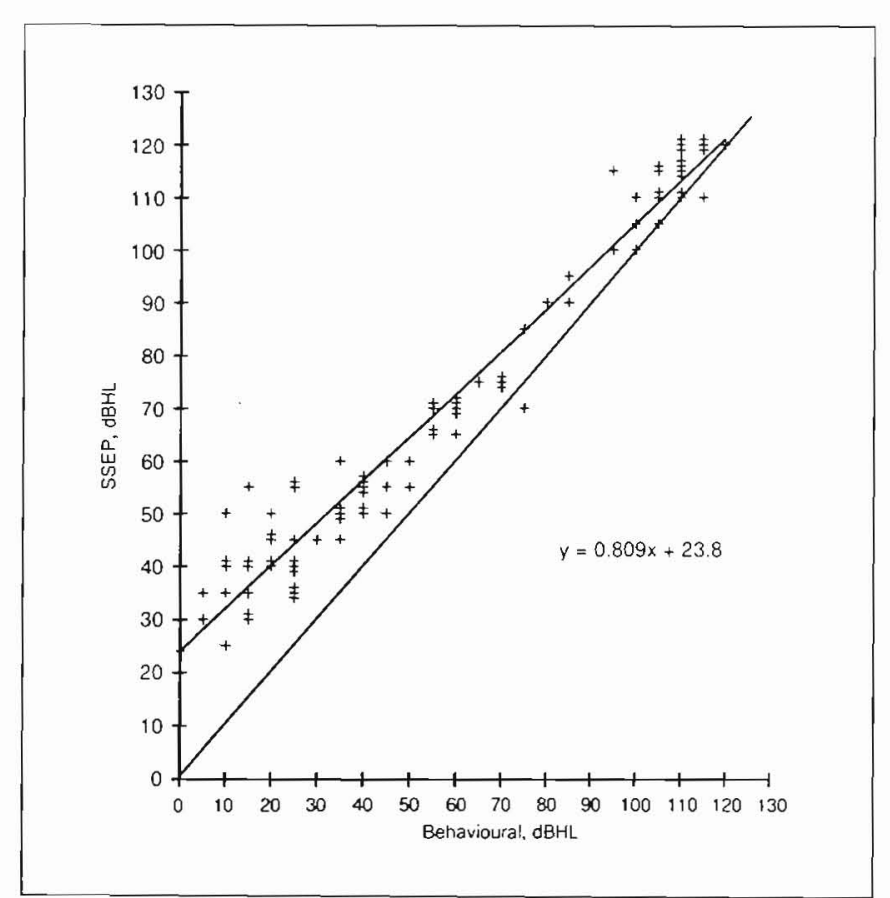

Fig. 1. Regression line analysis of threshold estimation using the SSEP technique in sleeping subjects to $1,000-\mathrm{Hz}$ tones amplitude and frequency modulated at $90 \mathrm{~Hz}$. Shown are the SSEP thresholds versus behavioural thresholds for 25 profoundly hearing impaired children, and 35 adults with mild to severe losses.

the observed SSEP threshold was found to be within $10 \mathrm{~dB}$ of that predicted by the regression line. Discrepancies of greater than $10 \mathrm{~dB}$ were only seen at the 250-, 500-, and $1,000-\mathrm{Hz}$ carrier frequencies.

Of the 25 cochlear implant candidates included in this study, 14 showed only low frequency residual hearing $(<1 \mathrm{kHz})$ when assessed behaviourally. SSEP testing carried out in the high frequencies on these subjects revealed no response to the stimuli at maximum levels indicating that artifactual responses were not contaminating the results.
In many cases the SSEP thresholds in the low frequencies were less than the behavioural thresholds in the octave frequency above, confirmin that the responses to these frequency specific stimuli are likely to be originating from the appropriate place in the cochlea.

\section{Discussion}

The preliminary results presented in this paper suggest that a lincar regression analysis can be used to predict behavioural thresholds from steady state evoked potential thresholds. Our data has shown that the use of the regression line will enable prediction of behavioural thresholds across a range of carrier frequencies, to within $10 \mathrm{~dB}$ accuracy on $96 \%$ of the occasions.

Threshold estimation using the SSEP technique, offers a number of advantages over other frequency specific evoked potential procedures in the assessment of young cochlear implant candidates. Middle latency and slow cortical responses for example, have been shown to be unreliable in young subjects due to maturational and sleeping effects.

Recent work using auditory brainstem responses to short duration tones in notched noise, has shown that threshold estimates in awake adul subjects can also be made with reasonable accuracy [6]. The evoked potential thresholds obtained from the normal and hearing impaired subjects in this paper were, however, more variable than those we obtained using the SSEP technique. Their results did show the improved accuracy with hearing impairment, and higher stimulus frequency seen in this study.

Another disadvantage of the ABR technique is that like all brief stimuli procedures, the equivalent $\mathrm{dBHL}$ levels at which it can test are limited. The continuous modulated tone used in the SSEP technique can be presented at levels as high as $120 \mathrm{dBHL}$, whereas click or brief tone stimuli are typically restricted to levels less than $100 \mathrm{dBnHL}$. This limitation is obviously a significant disadvantage when testing implant candidates with profound to total hearing losses

Another advantage which the SSEP procedure has over transient evoked response techniques is that it does not require subjective waveform analysis. The periodicity of the potential allows automated response detec tion systems such as the one used in this study, to be employed. This approach may in part account for the small variability in threshold estimates that we have observed. 
In summary, this test has shown a high degree of accuracy in the determination of hearing thresholds. The SSEP procedure is well suited as a measure of residual hearing in young cochlear implant candidates in that it can provide accurate thresholds to frequency-specific stimuli presented at high levels.

\section{References}

I Cohen LT, Rickards FW, Clark GM: A comparison of steady-statc evoked potentials to modulated tones in awake and sleeping humans. J Acoust Soc Am 1991;90:24672479.

2 Kuwada S, Batra R, Maher VL: Scalp potentials of normal and hcaring impaired subjects in response to sinusoidally amplitude-modulated tones. Hear Res 1986;21: 179-192.

3 Stapells DR, Picton TW, Smith AD: Prediction of audiometric thresholds in normal and hcaring impaired subjects using the $40 \mathrm{~Hz}$ event related potential. Canadian Speech and Hearing Association Annual Convention, May 1983, Montreal.

4 Tan LE, Rickards FW, Cohen LT: Neonatal hearing screening using steady-state evoked potentials. Aust J Audiol 1988;(suppl 3).

5 Rickards FW, Wilson OJ, Tan LE, Cohen LT: Steady-state evoked potentials in normal neonates. Aust J Audiol 1990;(suppl 4):21.

6 Stapells DR, Picton TW, Durieux-Smith A, Edwards CG, Moran LM: Thresholds for shor latency auditory evoked potentials to tones in notched noise in normalhearing and hearing impaired subjects. Audiology 1990;29:262-274.

G. Rance, Department of Otolaryngology, University of Melbourne,

East Melbourne, Vic. 3002 (Australia) 


\section{University Library}

\section{- M I N E R VA \\ A gateway to Melbourne's research publications}

Minerva Access is the Institutional Repository of The University of Melbourne

Author/s:

Rance, G.;Rickards, F. W.;Cohen, L. T.;Burton, M. J.;Clark, Graeme M.

Title:

Steady state evoked potentials: a new tool for the accurate assessment of hearing in cochlear implant candidates

Date:

1993

\section{Citation:}

Rance, G., Rickards, F. W., Cohen, L. T., Burton, M. J., \& Clark, G. M. (1993). Steady state evoked potentials: a new tool for the accurate assessment of hearing in cochlear implant candidates. In B. Frasysse \& O. Deguine (Eds.), Cochlear implants: new perspectives (pp. 44-48). Basel: Karger.

Persistent Link:

http://hdl.handle.net/11343/27341 